\title{
Competency-Based Evaluation Education: Four Essential Things to Know and Do
}

\author{
Cheryl Poth \\ University of Alberta \\ Michelle Searle \\ Queen's University
}

\begin{abstract}
Evaluator education must provide robust opportunities to support and assess the progressive, lifelong development of relevant knowledge and skills. If we wish to keep pace with the increasingly complex contexts in which evaluators operate, we need to better align our educational approaches with the global movement toward practice competencies guiding the profession. Key among the challenges is the lack of instructional guidance specific to a competency-based approach to evaluator education. In this practice note, we orient readers to the value of competency-based evaluation education and describe the teaching context using a systems perspective to examine the dynamic learning interactions and experiences. We advance four essential instructional features of the competency-based approach revealed by a study documenting the impacts on learning and student experiences. We conclude with lessons learned from reflecting upon our experiences during the development and implementation of a competency-based doctoral-level evaluation course to highlight the mutual benefits for learners and instructors.
\end{abstract}

Keywords: competency-based learning, evaluator education, instructional guidance

Résumé : La formation des évaluateurs et évaluatrices doit offrir de bonnes occasions d’appuyer et d'évaluer le développement progressif et continu des connaissances et des compétences pertinentes. Si nous voulons suivre l'évolution des contextes de plus en plus complexes dans lesquels les évaluateurs et évaluatrices travaillent, nous devons mieux centrer nos approches pédagogiques sur le mouvement mondial en faveur des compétences pratiques qui orientent la profession. L'un des principaux défis à relever est le manque de directives pédagogiques précises liées à une approche de formation fondée sur les compétences. Dans cette note sur la pratique, nous sensibilisons les lecteurs et lectrices à la valeur de la formation en évaluation fondée sur les compétences et décrivons le contexte de l'enseignement en utilisant une perspective systémique pour examiner les interactions et les expériences d'apprentissage dynamiques. Nous présentons quatre caractéristiques pédagogiques essentielles de l'approche axée sur les compétences révélées par une étude documentant ses impacts sur l'apprentissage et les expériences des

Corresponding author: Cheryl Poth, Centre for Research in Applied Measurement and Evaluation, Department of Educational Psychology, Faculty of Education, University of Alberta, 6-110 Education North, 11210-87 Avenue, Edmonton, AB, T6E 2G5; cpoth@ualberta.ca

(c) 2021 Canadian Journal of Program Evaluation / La Revue canadienne d'évaluation de programme 35.3 (Special Issue / Numéro spécial), 296-309 doi: 10.3138/cjpe.69577 
étudiants et étudiantes. Nous concluons l'article avec les leçons tirées de la réflexion sur nos expériences au cours de lélaboration et de la mise en cuvre d'un cours dévaluation axé sur les compétences (au niveau du doctorat) pour mettre en évidence les avantages mutuels pour les apprenants et apprenantes et les formateurs et formatrices.

Mots clés : apprentissage fondé sur les compétences, formation en évaluation, directives pédagogiques

Global demand exists for the practice of evaluation (Nielsen et al., 2018), as well as for effective pedagogical approaches supporting the personalized and developmental progression of relevant knowledge and skills over a lifetime as a professional evaluator within a changing world (Chappell et al., 2003). But while incorporating competencies into evaluation coursework can enhance learners' skills, knowledge, and abilities (Stevahn et al., 2005), evaluation-specific instructional guidance is lacking. In this practice note, we describe the lessons we've learned in the form of four essential instructional practices, revealed by a recent study of learners' experiences and outcomes during a competency-based doctorallevel evaluation course. We conclude with details about how the study informed subsequent course changes and future directions for this work.

\section{CONTEXTS SURROUNDING THE DEVELOPMENT AND IMPLEMENTATION OF THE COMPETENCY-BASED DOCTORAL-LEVEL EVALUATION COURSE}

Inspired by her experiences evaluating outcomes from a competency-based assessment system in medical education (e.g., Ross et al., 2009), the lead author (Poth) began to explore its potential in evaluation. A competency-based approach to evaluator education holds strong potential for addressing the need for robust opportunities supportive of the personalized and developmental progression of knowledge and authentic application of skills. Competency-based learning is described as an outcomes-based approach that challenges learners to assess their abilities, demonstrate achievement, and recognize areas for further learning (Frank et al., 2010). A competency-based approach is intuitive because incorporating competencies into evaluation coursework has long been recognized as useful for enhancing evaluation learners' skills, knowledge, and abilities (Stevahn et al., 2005). There exists a global movement toward establishing competencies and professionalizing the evaluation profession, evidenced by the recent work of the task force of the American Evaluation Association and Japanese Evaluation Association, among others. It is important to note, however, the lack of consensus that surrounds this movement.

Canadian evaluators are especially well positioned to be global instructional pioneers because a necessary precursor to the approach-the identification of profession-specific competencies-has been in place for Canadian evaluators since 2010. A taxonomy of essential evaluation practice competencies has the potential to serve as a useful pedagogical framework for those teaching evaluation. 
Gullickson and colleagues highlight the contribution of a common evaluation pedagogical framework as critical "so that all practitioners draw from a common pool of knowledge and embody accepted norms of conduct like principles and ethics, which are then communicated to groups outside the profession" (Gullickson et al., 2019, p. 9). The lead author's experiences providing evidence of her evaluator competency as part of the credentialing program run by the Canadian Evaluation Society (CES) in 2011 spurred her initial development of a doctorallevel, competency-based evaluation course at the University of Alberta.

In the years since, this course has undergone several iterations. During implementation of the fall 2018 course, we undertook a formal examination of the experiences that learners attributed to their self-reported competency gains (for full study description see Poth et al., 2020). In the published mixed-methods study, we discussed seven novel insights generated by a systems-informed case-study methodology. This unique study approach more accurately represented the complex learning environments that naturally influence evaluator education outcomes. The key instructional and institutional systems influences, represented in Figure 1, included instructor and learner expectations, past teaching and learning experiences, interactions with other learners, and faculty course expectations and logistics. Everyone involved was influenced by the learning that occurred, the interactions with one another, and the dynamic societal and global contexts surrounding them. We recognized that individual learners' prior experiences affect the elements of learning and contribute to individual differences in the types of connections that learners make with new experiences (Knowles et al., 2012). One key study outcome involved advancing the following definition guiding our current work:

A competency-based approach for evaluator education is an approach to preparing evaluators for real-world practice and supporting their lifelong development as evaluators organized around evaluator competencies derived from an ongoing analysis of societal needs. It is distinguishable by being learner-centred and focused on a time independent developmental learning progression of mastery (Poth et al., 2020, p. 14).

\section{DESCRIBING THE COURSE DESIGN AND IMPLEMENTATION COMPRISING THE TEACHING CONTEXT}

Designing and implementing a high-quality competency-based evaluation course requires alignment among course outcomes, course experiences, and course evidence, as depicted in Figure 2.

Our course logistics were constrained by the schedule of 13 weekly threehour face-to-face classes, supplemented by online discussions and resources. Of particular note is the "backwards design" (e.g., Fink, 2013; Wiggins \& McTighe, 2005) and "constructive alignment" (Biggs, 2014) approach to planning as the backbone of the competency-based evaluation course. This involves the instructor initially identifying the course outcomes, then determining acceptable course evidence, and then designing course experiences to support learners' development of the competencies outlined as the course outcomes. For the 2018 course iteration 


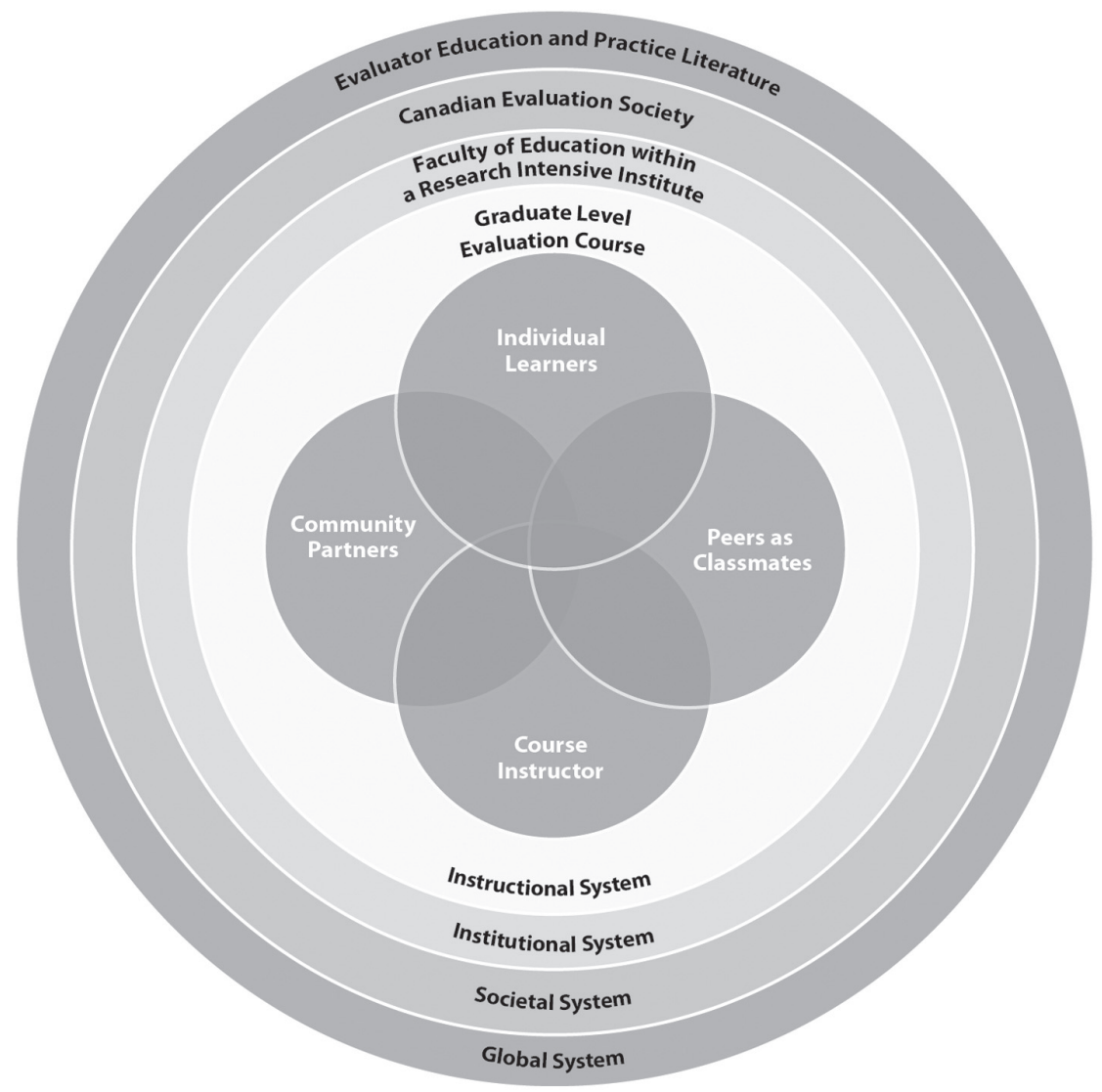

Figure 1. The complex course learning environment

studied in the published report (Poth et al., 2020), the instructor identified 15 competencies from the initial framework CES (2018) as the course outcomes, four summative assessments as the course evidence (evaluation design, issue examination, discussion facilitation, and competency assessment and reflection), and four types of feedback-embedded instructional activities occurring in person and as the course experiences (large group discussions about community partnership development, small group review of work-in-progress for the evaluation design, instructor facilitation of real-world evaluation skill applications, and engagement with diverse perspectives through readings, guest speakers, and video links).

\section{OUR REFLECTION, LESSONS LEARNED, AND FOUR ESSENTIAL INSTRUCTIONAL PRACTICES}

The lessons we learned from reflecting upon the 2018 course implementation are organized into four essential instructional practices for those teaching or planning 


\section{CES competencies as} Course Outcomes
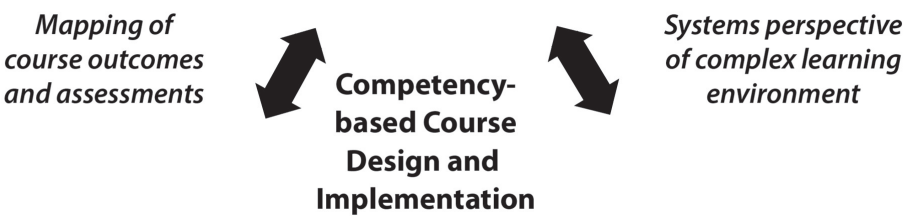

Implementation

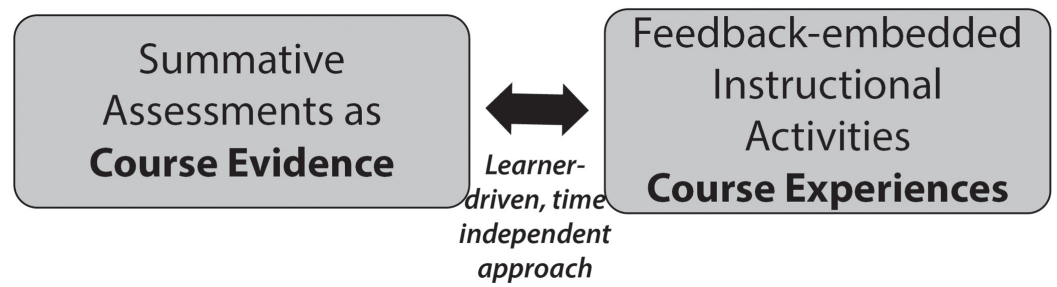

Figure 2. Key components of the competency-based evaluation course design and implementation

to teach evaluation using a competency-based approach. We undertook a structured reflection of our findings from the 2018 course implementation, and these novel understandings begin to address the dearth of information about how the CES competencies influence the design and implementation of evaluator education in Canada (Galport \& Azzam, 2017). Importantly, given that the availability of evaluation-specific term-length courses within Canada (CUEE, 2008) and beyond (Christie et al., 2014) remains limited, these insights and instructional guidance are broadly transferable across evaluation education opportunities to include workshops and short courses.

1. Maintain relevancy of course outcomes with competency revisions within the evaluation profession to keep pace with real-world practice expectations. Our findings suggest that learners recognized the assessments as generating evidence of their competency gains, and the course experiences as helping prepare them for success on the assessments. As the course was being implemented during fall 2018, the revised CES competencies were launched to reflect evolutions in the field. This highlights the need for our approaches to evaluator education to accommodate further revisions expected over time. We propose competency-based approaches that can easily accommodate revisions to the course outcomes and that can help learners and instructors stay current with the professional evaluator practice competencies necessary for the dynamic contexts in which evaluators are expected to operate. 
2. Scaffold experiential learning opportunities to navigate the messiness of real-world evaluation practice. Over the past decade, while the course has undergone significant changes in response to learner feedback, the central role of experiential engagement with a community client to create an evaluation plan has remained. This experience involves rendering service without payment because the learner completes the evaluation design assignment toward course credit. Our findings suggest that behind-thescenes support through class discussions and one-on-one instructor consultations provides an authentic yet supportive experience for learners working with their community clients. When learners have experiences in which they are supported as they navigate dynamic interactions, they are better able to bridge theory and practice in their work. This reflects and extends the well-established need for practical and hands-on experiences to complement more didactic approaches to developing the requisite complement of evaluator skills and dispositions in an applied field (e.g., Chouinard et al., 2017; Chelimsky, 1997; Fitzpatrick, 1994). We propose that competency-based approaches can generate evidence of developing the complex skills necessary for real-world evaluation practice by assessing different combinations of individual competencies in the assignments.

3. Create opportunities for learner-centred choice to enhance engagement in their own evaluation learning. Our findings consistently revealed the importance, from the learners' perspective, of opportunities for pursuing areas of personalized interest and goals. Specifically, learners referred to their choice in selecting the community partner for the evaluation design and defining an issue topic examined in another assignment as helping them to reach their own goals for the course. It is not surprising that engaging learners more actively in their own learning is beneficial, and that choice helps. This highlights the need for learners to have opportunities to take responsibility for their own learning as lifelong professionals in realistic evaluation practice contexts involving the interplay among people, program, politics, and the environment (Alkin et al., 2012). We propose that learners direct their own learning as a key tenet of competency-based approaches, positioning novice evaluators for the lifelong learning they will be expected to engage in as evaluation professionals.

4. Promote metacognitive practices to build learners' awareness of their own learning progression. To support the elaboration of metacognition, we embedded self-reflection on learners' own competency development into the final assignment; our findings suggest that learners demonstrated the ability to self-assess progress and identify areas for further development. When these emerging understandings are discussed within established communities of practice, such as with peers and instructor in the course environment, all learners can benefit. It is not surprising that 
reflection helps learners build awareness of their own learning. The theoretical foundations of experiential learning include the work of Dewey, Piaget, and Vygotsky. At the centre of this work is the use of reflection and active participation to make sense of lived experiences. Dewey's (1933) statement that not all experience results in learning highlights the contribution of high-quality reflection on course experiences. Similar to the work of Chouinard et al. (2017), our study highlights the learning advantages afforded to novice evaluations from authentic learning opportunities and a competency-based approach with access to ongoing feedback as core characteristics with the strong potential to contribute to reflective practices.

\section{COURSE CHANGES AND FUTURE DIRECTIONS FOR THIS WORK}

Based on our reflection and informed by the formal examination of the 2018 course implementation, we made changes to the 2019 course design and implementation that have not been discussed elsewhere. First, we adopted the revised 2018 CES competencies to reflect evolving practice needs and expanded the number of competencies identified as course outcomes to 23 of the 36 Canadian Evaluation Competencies (CES, 2018) across the five evaluator practice domains (see Table 1). We grappled with how many competencies to include as course outcomes and decided to categorize them as primary and complementary (see Appendix for list). This expansion of course outcomes was informed by learnerreported developments in competencies beyond what the instructor initially identified in the 2018 course iteration. Course design was again structured using "backwards design," starting with the end in mind (Fink, 2013).

The change in learner outcomes had a ripple effect on revisions to the course assessments (see Table 2) and to the course experiences supporting their development. (See Appendix for how each course assessment was designed to generate evidence of different combinations of the individual competencies representing the intended course outcomes, and notice the emphasis on the competency "Uses self-awareness and reflective thinking to continually improve practice" across all four assessments.) This enhanced role of reflective practice is apparent across the revised assignments, including, for example, through the inclusion of an explicit learning plan in the initial competency assessment that also creates more explicit opportunities for learners to articulate their course goals and how they hope to achieve them.

A similar, expanded emphasis on the competency "Engages in reciprocal processes in which evaluation knowledge and expertise are shared between the evaluator and stakeholders to enhance evaluation capacity for all" as a primary course outcome reflects a focus on scaffolding experiential learning opportunities to navigate the messiness of real-world practice. The enhanced role of scaffolding is apparent across the experiences embedded within the course, for example, through the inclusion of feedback opportunities throughout the course on design 
Table 1. Revised 2019 course outcomes adopting 2018 CES competencies.

\begin{tabular}{|c|c|c|c|}
\hline \multirow[t]{2}{*}{$\begin{array}{l}\text { CES competency } \\
\text { practice domains }\end{array}$} & \multirow[t]{2}{*}{ Description of CES practice domain focus } & \multicolumn{2}{|c|}{$\begin{array}{l}\text { CES competencies } \\
\text { (2018) }\end{array}$} \\
\hline & & Total & $\begin{array}{l}\text { Course } \\
\text { targeted }^{\mathrm{a}}\end{array}$ \\
\hline Reflective & $\begin{array}{l}\text { Knowledge of evaluation theory and } \\
\text { practice; application of evaluation } \\
\text { standards, guidelines, and ethics; and } \\
\text { awareness of self, including reflection } \\
\text { on one's practice and the need for } \\
\text { continuous learning and professional } \\
\text { growth. }\end{array}$ & 8 & 3 \\
\hline Technical & $\begin{array}{l}\text { Strategic, methodological, and } \\
\text { interpretive decisions required to } \\
\text { conduct an evaluation. }\end{array}$ & 10 & 7 \\
\hline Situational & $\begin{array}{l}\text { Understanding, analyzing, and attending } \\
\text { to the many circumstances that make } \\
\text { every evaluation unique, including } \\
\text { culture, stakeholders, and context. }\end{array}$ & 7 & 5 \\
\hline Management & $\begin{array}{l}\text { Applying sound project management } \\
\text { skills throughout the evaluation project. }\end{array}$ & 6 & 3 \\
\hline Interpersonal & $\begin{array}{l}\text { Social and personal skills required to } \\
\text { communicate and interact effectively } \\
\text { with all stakeholders. }\end{array}$ & 5 & 5 \\
\hline
\end{tabular}

a Targeted refers to identification as a learner outcome during instructional design and as assessed by course assignments; however, additional competencies may develop.

drafts from the community partner, instructor, and peers using both online and in-person interactions.

In closing, this practice note provides a glimpse into what is often inaccessible when planning, implementing, and assessing a teaching innovation, with insights related to four essential instructional practices for those implementing a competency-based approach to evaluation education. Designing effective competency-based evaluator education requires understandings of who the learners are, how to facilitate meaningful interactions among those involved in the course, what practical experiences optimize individual and collective growth potential, and how to assess evidence of complex learning outcomes. When such skills are in place, both learners and instructors can benefit from the continuing development and improvement of effective, competency-based learning environments. Our course changes reflect our own experiences as evaluation educators and graduate-student supervisors and point to the essential role of contextualized community experiences and engaging in reflective practice in preparing 


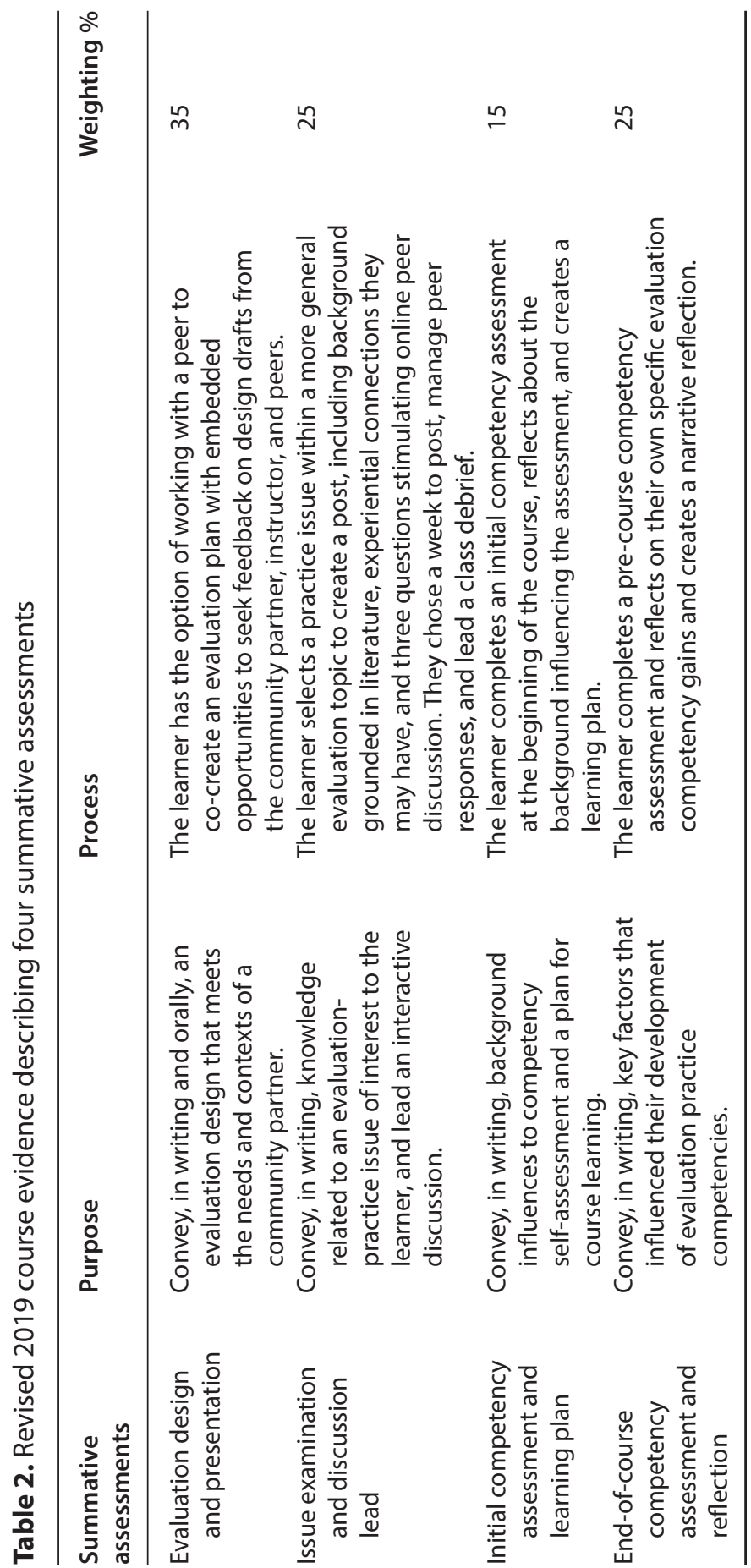


evaluators for the realities experienced in the field (Poth et al., 2017). We draw upon our combined decades of pedagogical and evaluator educator experience in our recent implementation study and subsequent course changes. This has resulted in crystallization of our learning, which allows us some degree of confidence to elucidate the four instructional practices. We offer the following "take-away" messages for evaluation instructors to keep in mind in their own pedagogical practice when using competency-based approaches:

- $\quad$ use backward design in your planning of course outcomes, evidence, and activities;

- embed opportunities for your learners to build awareness of themselves and their learning through reflective practice;

- facilitate reciprocal learning environments that draw upon diverse perspectives of those involved in your course and course materials; and

- create your course assessments to embed choice and measure several competency outcomes so that they are personalized and target more complex skills.

Competency-based approaches in evaluation offer great potential for keeping pace with the increasingly complex contexts in which evaluators operate and with the professional competency frameworks, and they encourage lifelong learning. We anticipate that future research will generate further evidence of the effectiveness of competency-based approaches across diverse evaluator education contexts.

\section{REFERENCES}

Alkin, M. C., Vo, A. T., \& Christie, C. A. (2012). The evaluator's role in valuing: Who and with whom. New Directions for Evaluation, 2012(133), 29-41. https://doi.org/10.1002/ ev.20004

Biggs, J. (2014). Constructive alignment in university teaching. HERDSA Review of Higher Education, 1, 5-22.

Canadian Evaluation Society (CES). (2018). Competencies for Canadian evaluation practice. https://evaluationcanada.ca/competencies-canadian-evaluators

Chappell, C., Tennant, M., Yates, L., Solomon, N., \& Rhodes, C. (2003). Reconstructing the lifelong learner pedagogy and identity in individual, organisational and social change. RoutledgeFalmer.

Chelimsky, E. (1997). The coming transformations in evaluation. In E. Chilimsky \& W. R. Shadish (Eds.), Evaluation for the 21st century: A handbook (pp. 1-26). Sage.

Chouinard, J. A., Boyce, A. S., Hicks, J., Jones, J., Long, J., Pitts, R., \& Stockdale, M. (2017). Navigating theory and practice through evaluation fieldwork: Experiences of novice evaluation practitioners. American Journal of Evaluation, 38(4), 493-506. https://doi. org/10.1177/1098214016667582 
Christie, C. A., Quiñones, P., \& Fierro, L. (2014). Informing the discussion on evaluator training: A look at evaluators' course taking and professional practice. American Journal of Evaluation, 35(2), 274-290. https://doi.org/10.1177/1098214013503697

Consortium of Universities for Evaluation Education (CUEE). (2008). CUEE: About us, goals and objectives. http://evaluationeducation.ca

Dewey, J. (1933). How we think. Heath \& Co.

Fink, L. D. (2013). Creating significant learning experiences: An integrated approach to designing college courses (2nd ed.). Jossey-Bass.

Fitzpatrick, J. L. (1994). What should an evaluation program look like: Alternative models for structuring professional preparation programs. In J. W. Altschuld \& M. Engle (Eds.), The preparation of professional evaluators: Issues, perspectives, and current status. New Directions for Program Evaluation, No. 62 (pp. 1-94). Jossey-Bass.

Frank, J. R., Snell, L. S., Cate, O. T., Holmboe, E. S., Carraccio, C., Swing, S. R., Harris, P., Glasgow, N. J., Campbell, C., Dath, D., Harden, R. M., Iobst, W., Long, D. M., Mungroo, R., Richardson, D. L., Sherbino, J., Silver, I., Taber, S., Talbot, M., \& Harris, K. A. (2010). Competency-based medical education: Theory to practice. Medical Teacher, 32(8), 638-645. https://doi.org/10.3109/0142159x.2010.501190

Galport, N., \& Azzam, T. (2017). Evaluator training needs and competencies: A gap analysis. American Journal of Evaluation, 38(1), 80-100. https://doi.org/10.1177/1098 214016643183

Gullickson, A. M., King, J. A., LaVelle, J. M., \& Clinton, J. M. (2019). The current state of evaluator education: A situation analysis and call to action. Evaluation and Program Planning, 75, 20-30. https://doi.org/10.1016/j.evalprogplan.2019.02.012

Knowles, M. S., Holton, E. F., \& Swanson, R. A. (2012). The adult learner: The definitive classic in adult education and human resource development. Routledge.

Nielsen, S. B., Lemire, S., \& Christie, C. A. (2018). The evaluation marketplace and its industry. In S. B. Nielsen, S. Lemire, \& C. A. Christie (Eds.). The evaluation marketplace: Exploring the evaluation industry. New Directions for Evaluation, 160, 13-28.

Poth, C., Anderson-Draper, M., \& El Hassar, B. (2017). Influential mentoring practices for navigating challenges and optimizing learning during an evaluation internship experience. Canadian Journal of Program Evaluation, 31(3), 374-396. https://doi. org/10.3138/CJPE.325

Poth, C., Searle, M., Aquilina, A., Ge, J., \& Elder, A. (2020). Assessing competency-based evaluation course impacts: A mixed methods case study. Evaluation and Program Planning, 79, Article 101789. https://doi.org/10.1016/j.evalprogplan.2020.101789

Ross, S., Poth, C., Donoff, M., Papile, C., Humphries, P., Stasiuk, S., \& Georgis, R. (2012). Involving users in the refinement of the competency-based achievement system: An innovative approach to competency-based assessment. Medical Teacher, 34, e143e147. https://doi.10.3109/0142159X.2012.644828

Stevahn, L., King, J. A., Ghere, G., \& Minnema, J. (2005). Establishing essential competencies for program evaluators. American Journal of Evaluation, 26(1), 43-59. https://doi. org/10.1177/1098214004273180

Wiggins, G., \& McTighe, J. (2005). Understanding by design (2nd ed.). Association for Supervision and Curriculum Development. 


\section{AUTHOR INFORMATION}

Cheryl Poth is professor in the Centre for Applied Measurement and Evaluation within the Department of Educational Psychology, Faculty of Education, University of Alberta, and a co-founder of the Alberta Clinical and Community-Based Evaluation Research Team. Her research interests include evaluation use with particular emphasis on developmental, participatory, and collaborative evaluation approaches.

Michelle Searle is an assistant professor of educational evaluation at Queen's University. She holds the Credentialed Evaluator (CE) designation from the Canadian Evaluation Society and is a member of the Ontario College of Teachers (OCT). Michelle focuses on increasing the usefulness of program evaluation through collaborative approaches and innovative forms of dissemination. 


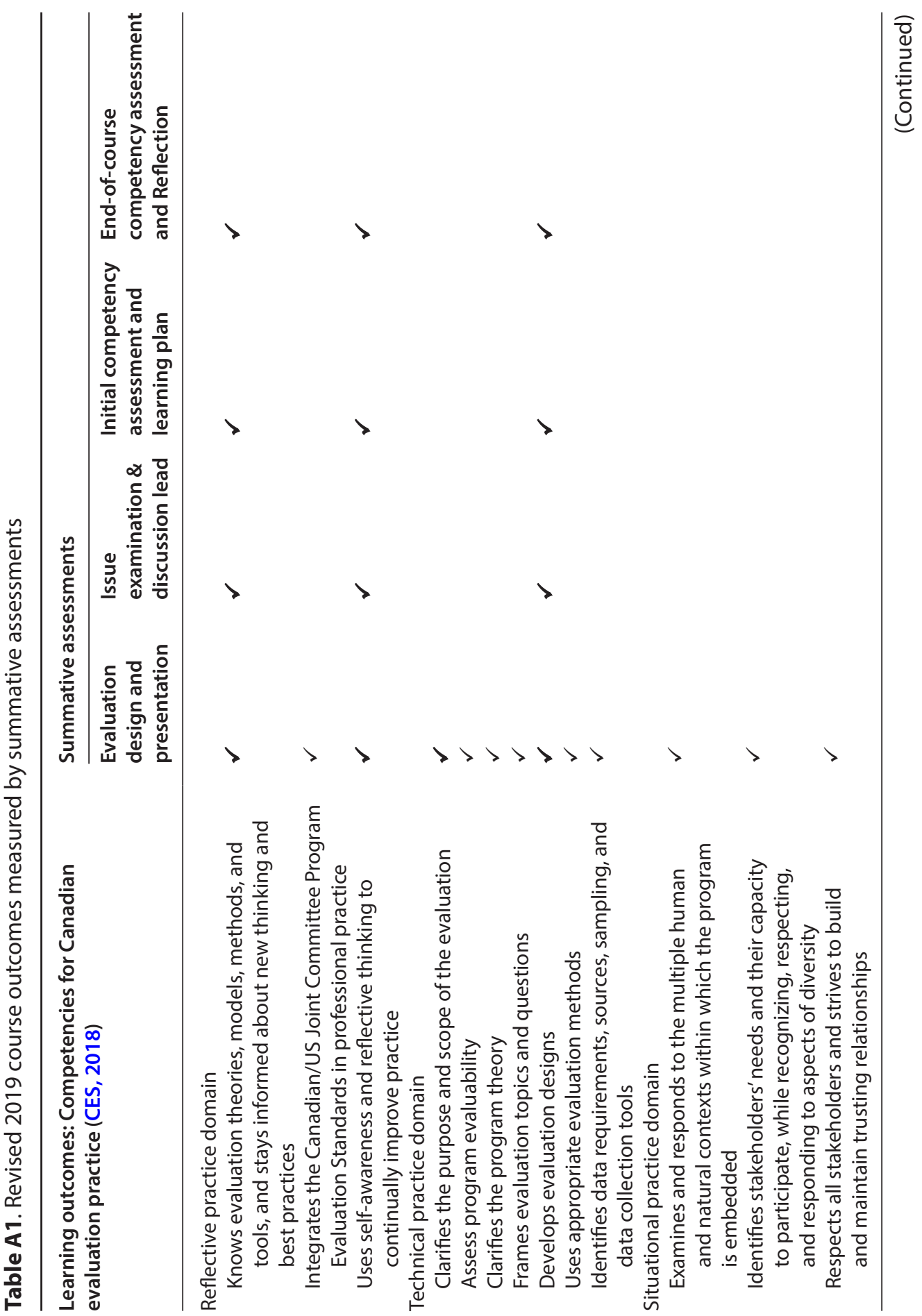




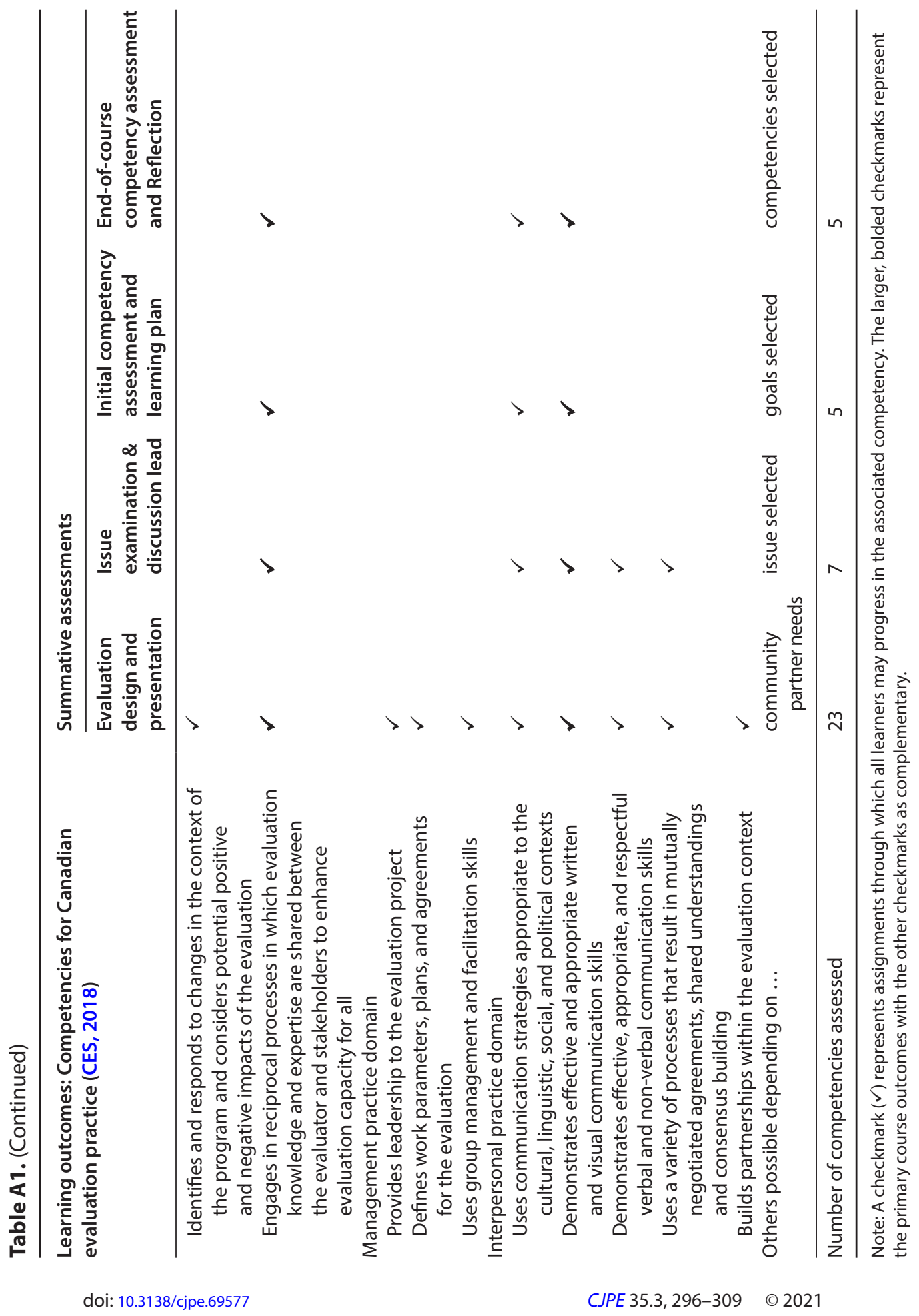

